$$
\begin{aligned}
& \text { روبينه بإسمئٍ } \\
& \text { اسرمحورخان } \\
& \text { كار اروواوب }
\end{aligned}
$$

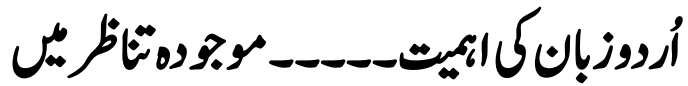

\section{Rubina Yasmin}

Scholar PhD Urdu, Department of Urdu, Islamia College University, Peshwar.

\section{Asad Mehmood Khan}

Scholar PhD Urdu, Department of Urdu, Islamia College University, Expert, Urdu Literature.

\section{Importance of Urdu Language....In the current context}

Urdu language is the identity, symbol and biggest memorandum of our national and Islamic tradition. It is the trustee of our identity because it rich literature, culture and historical background. Urdu language has proved its importance because of its harmony and vastness. There is no doubt it is world wide popular language, but unfortunately it has not achieved the status that it deserve in their own country Pakistan. Urdu priority is given to English. In this situation we need to consider the due status of our national language that is sign of our identity. In following article enlighted the importance of Urdu.

Key Words: Memorandum, Trustee, Literature, Historical Background, Vastness, Popular Language, National Language.

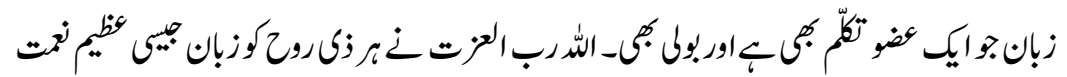

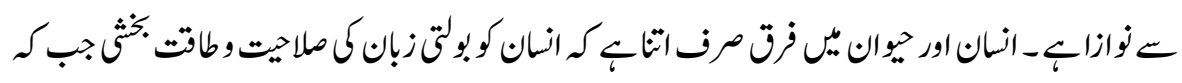

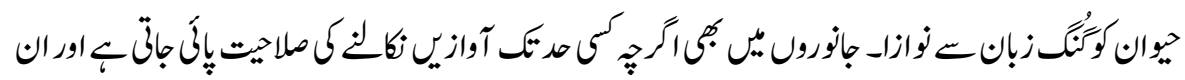

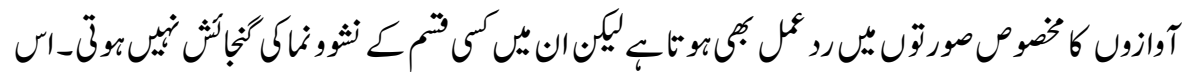

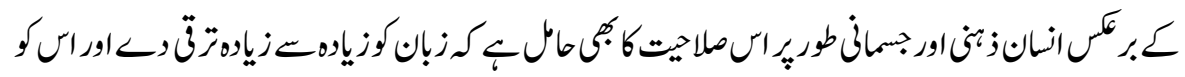




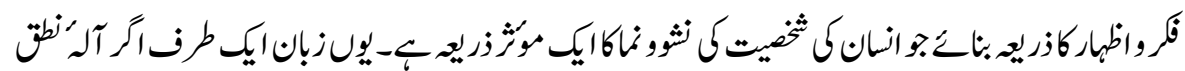

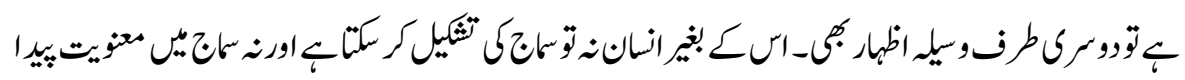

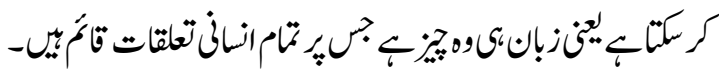

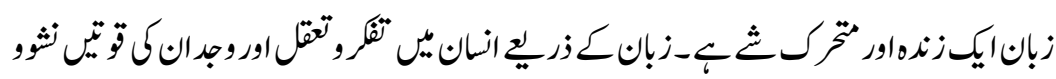

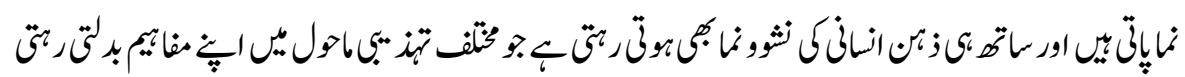

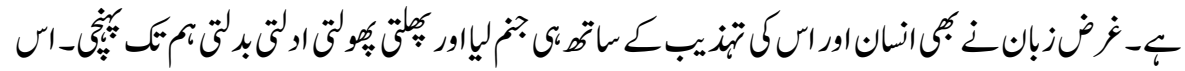

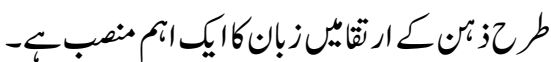

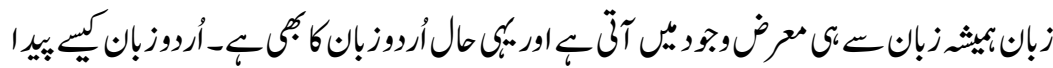

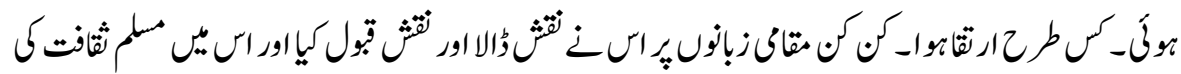

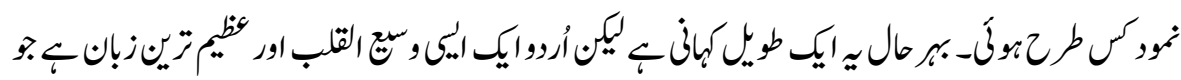

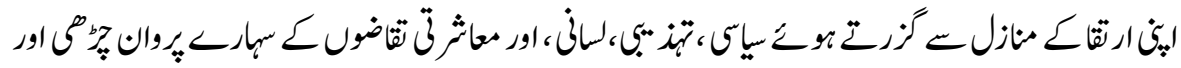

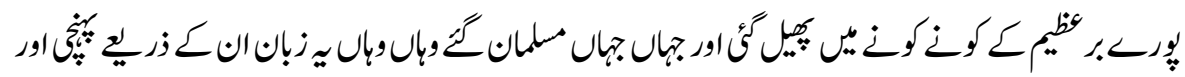

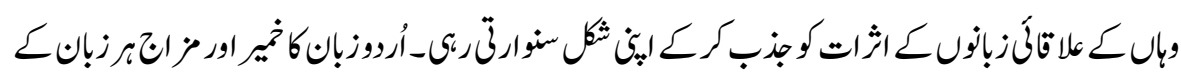

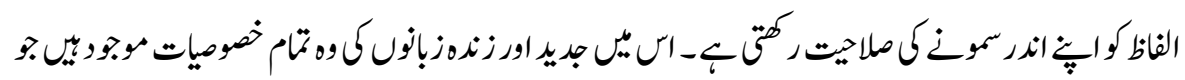

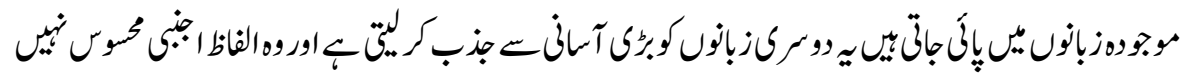

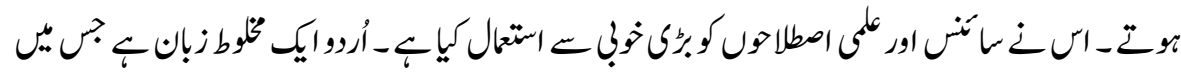

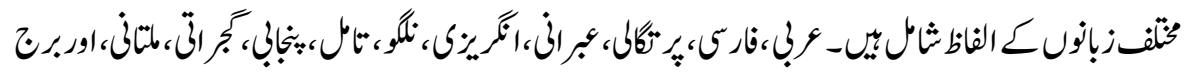

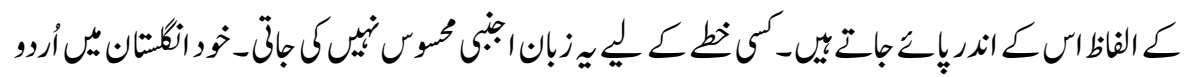

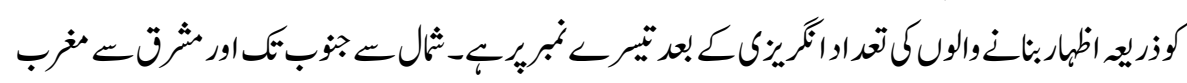

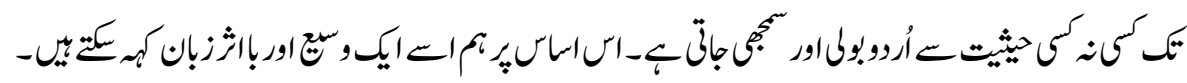

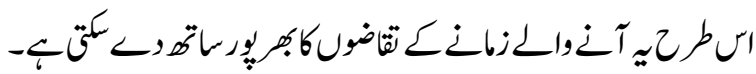

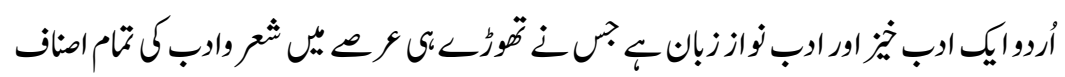

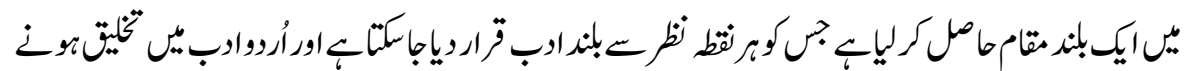




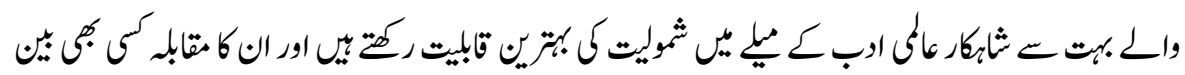

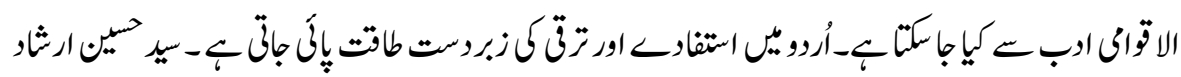

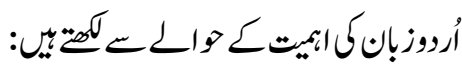

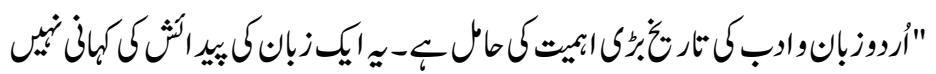

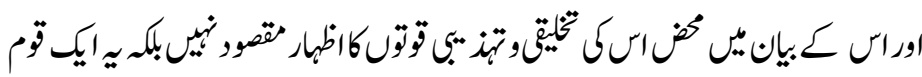

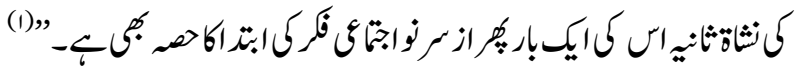

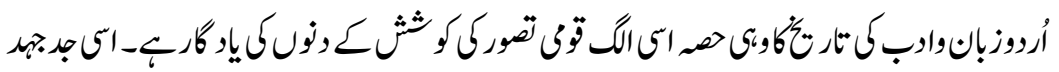

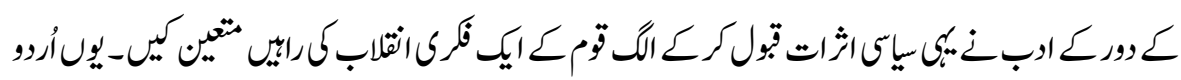

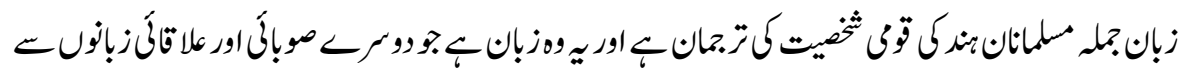

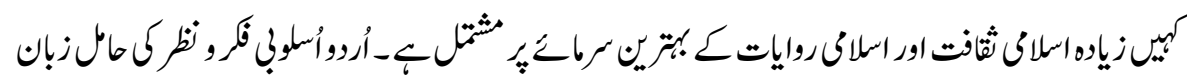

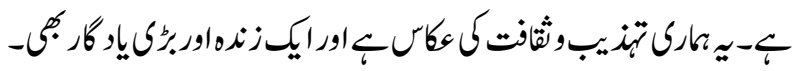

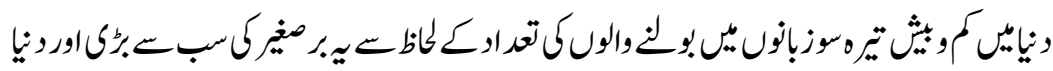

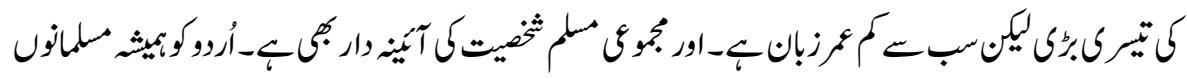

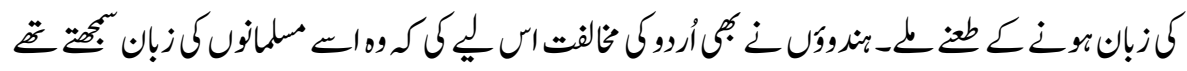

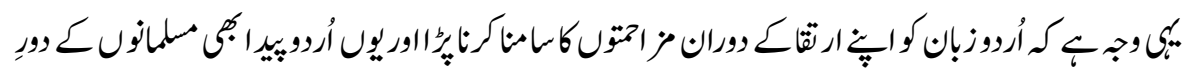

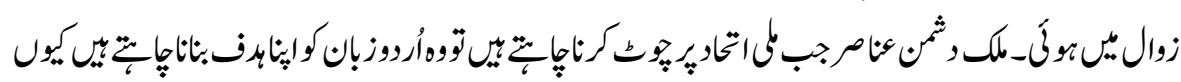

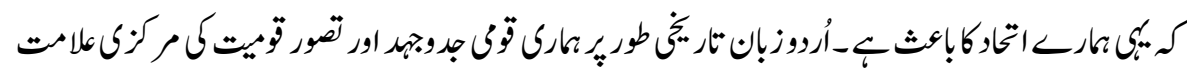

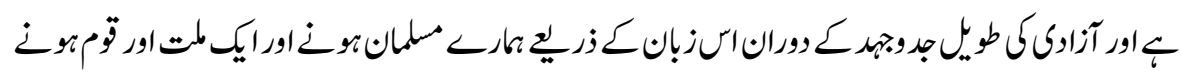

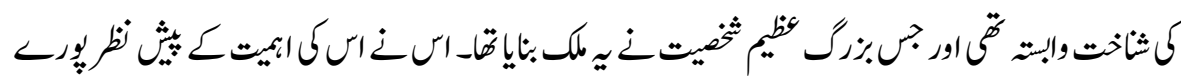

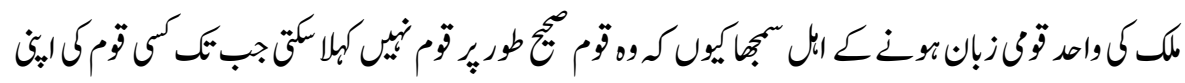

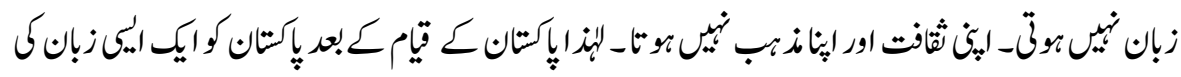

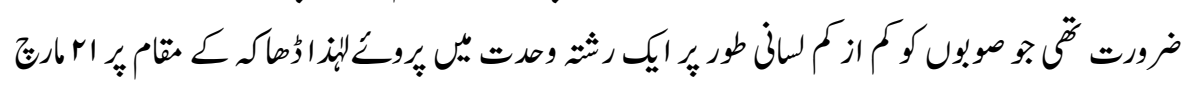

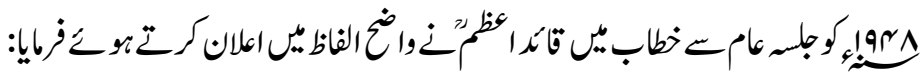




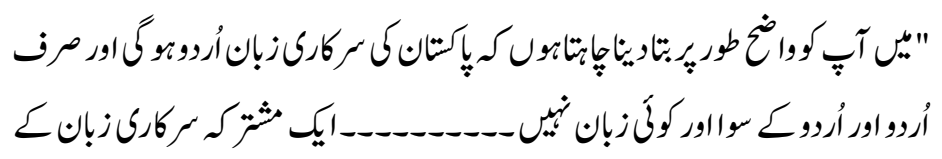

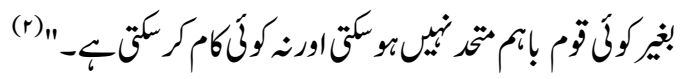

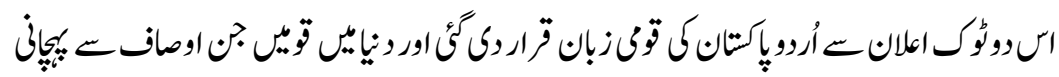

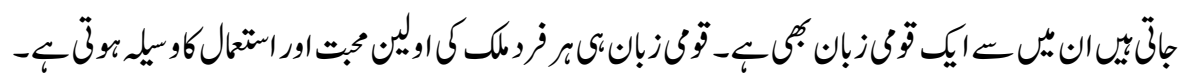

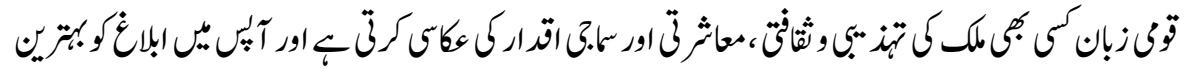

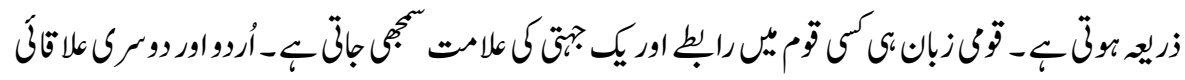

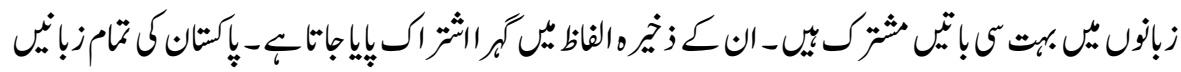

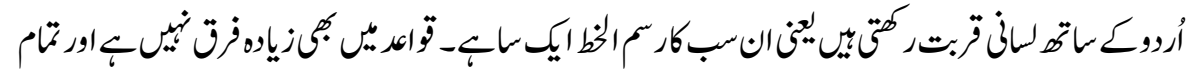

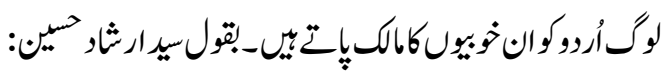

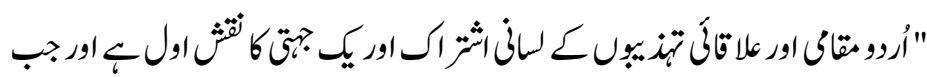

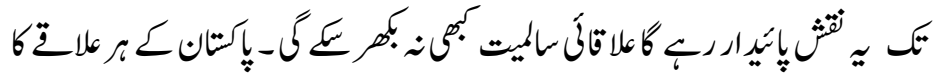

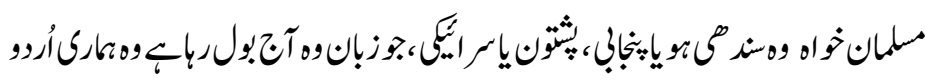

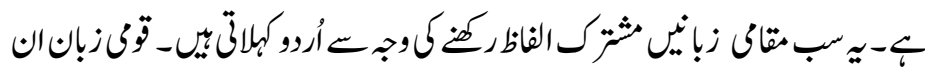

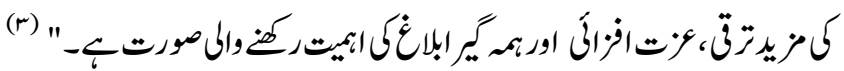

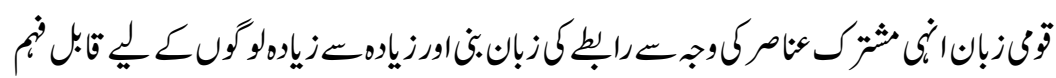

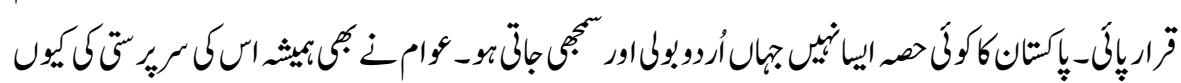

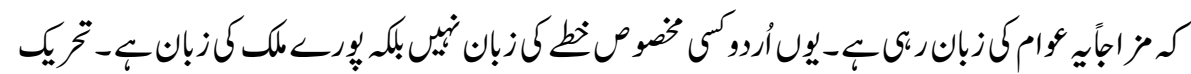

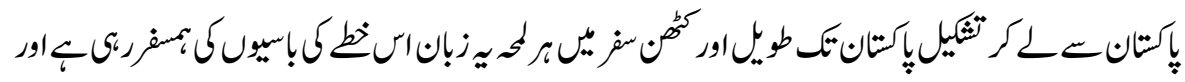

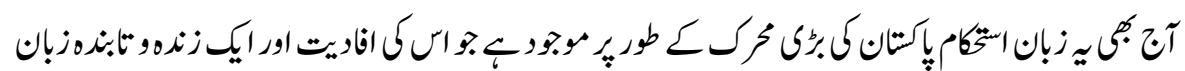

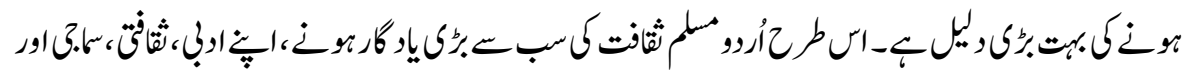

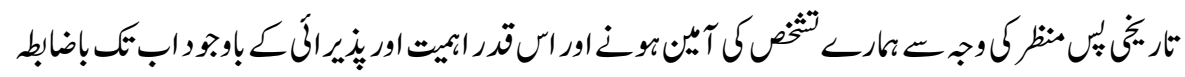

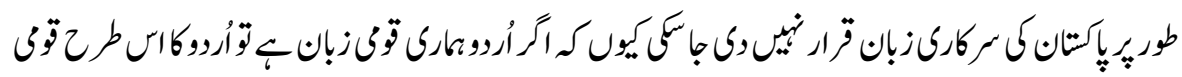




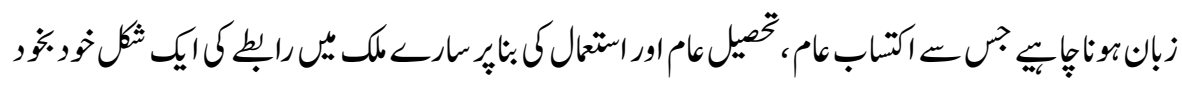

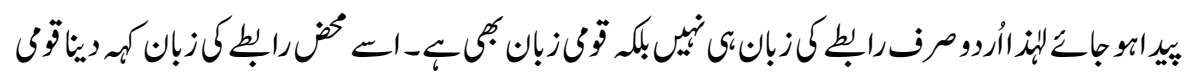

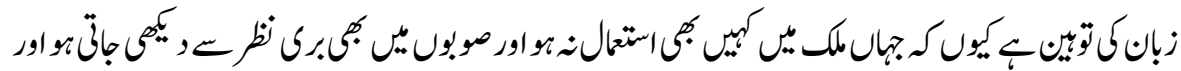

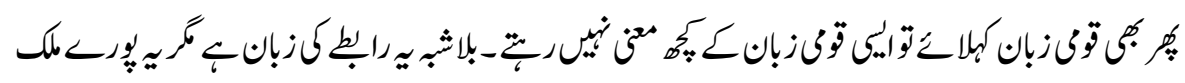

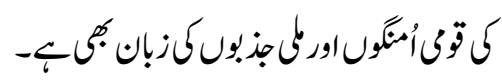

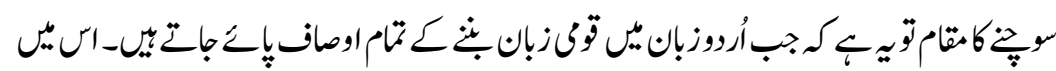

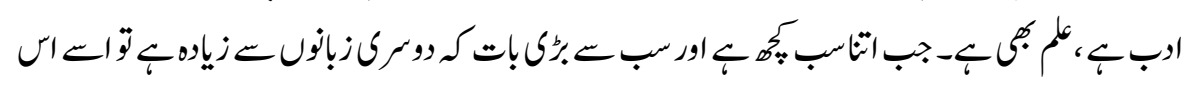

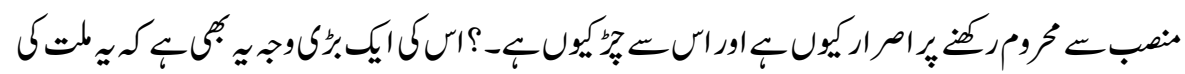

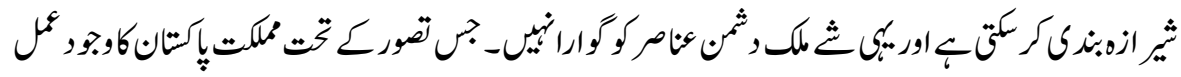

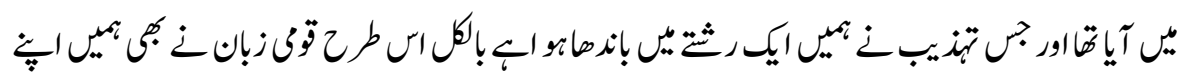

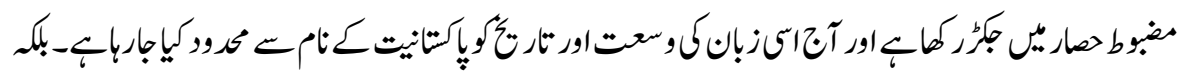

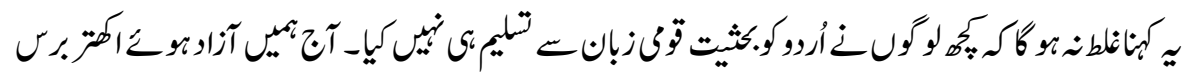

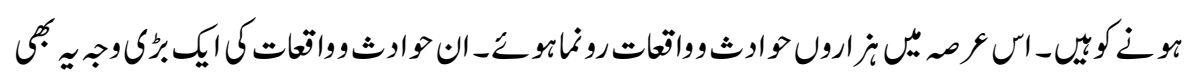

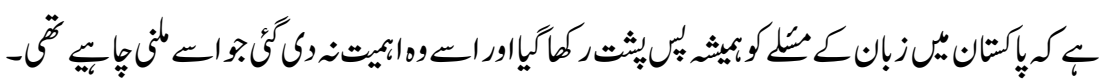

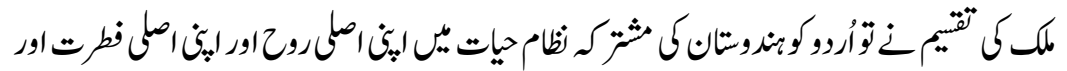

روايات

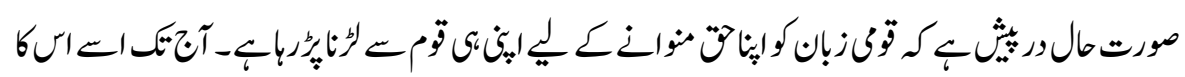

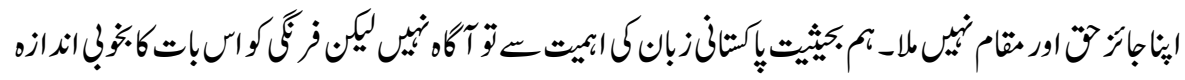

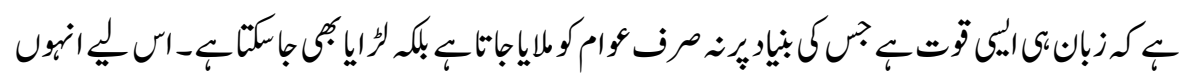

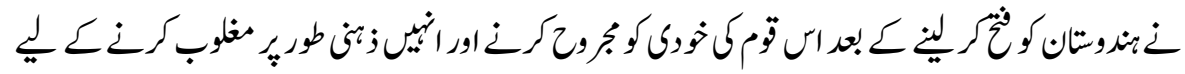

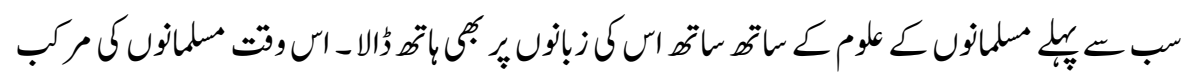

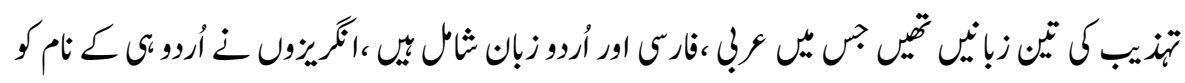

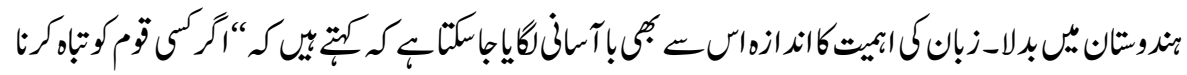




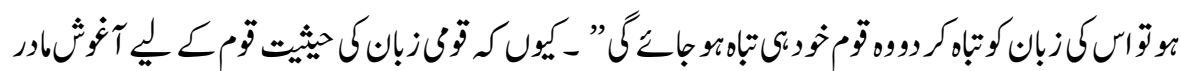

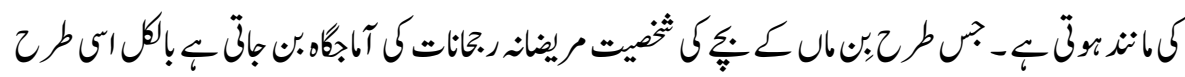

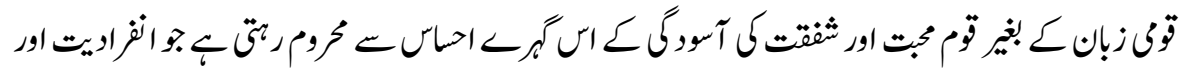

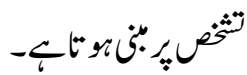

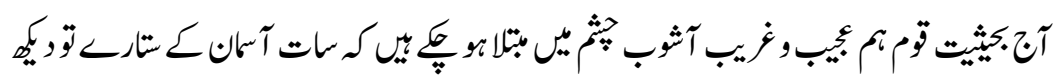

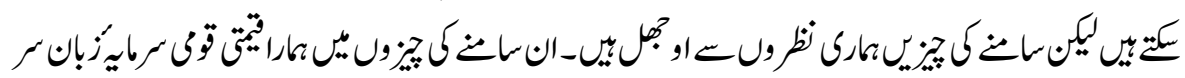

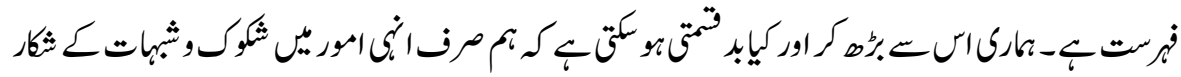

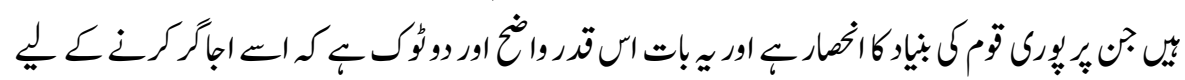

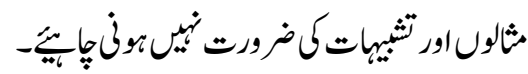

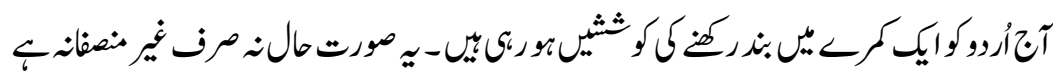

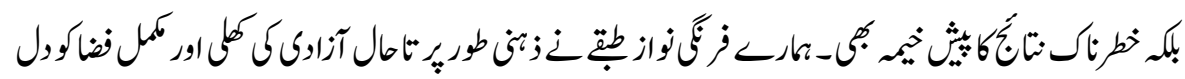

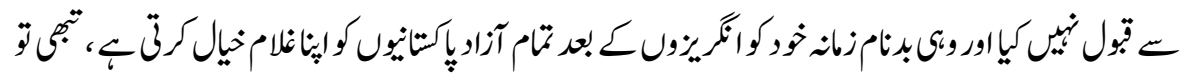

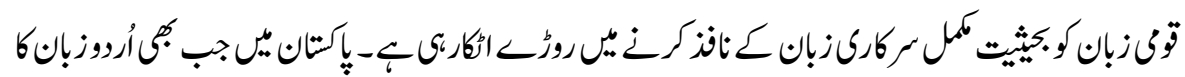

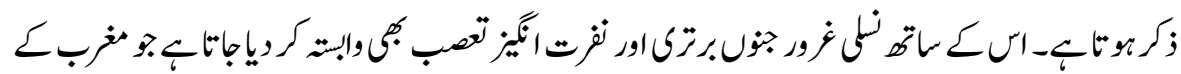

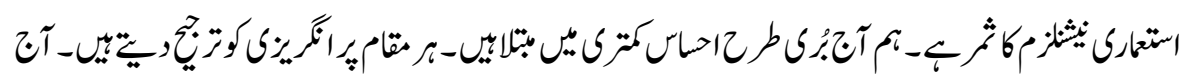

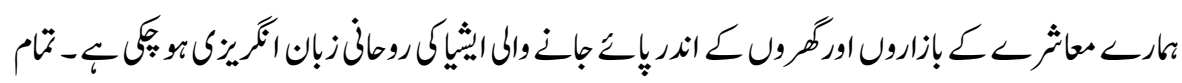

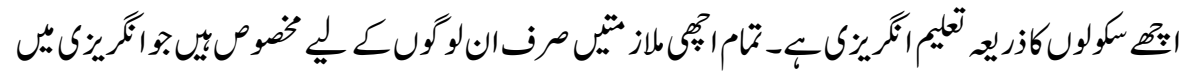

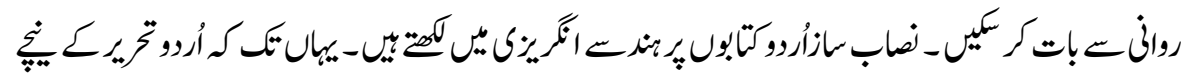

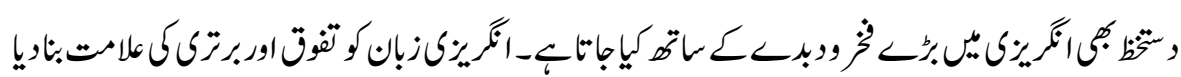

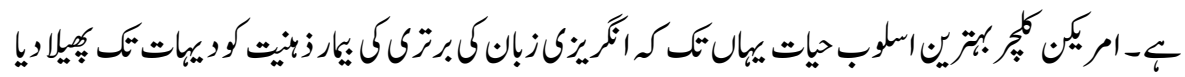

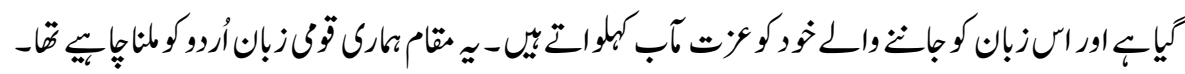

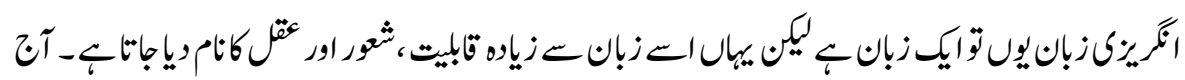

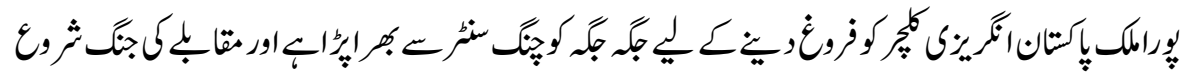




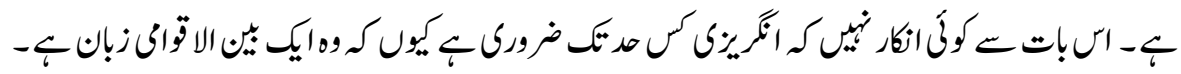

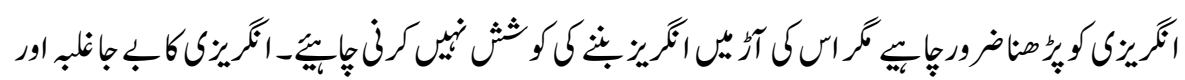

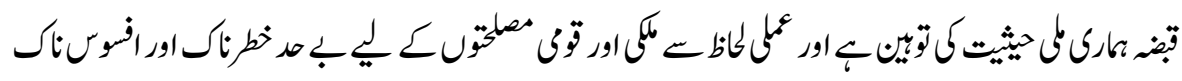

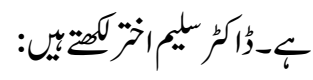

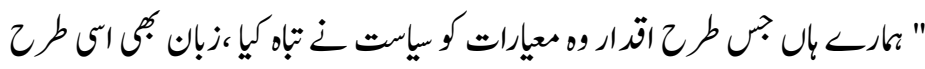

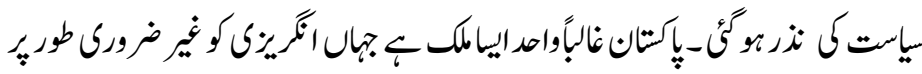

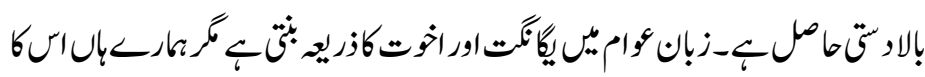

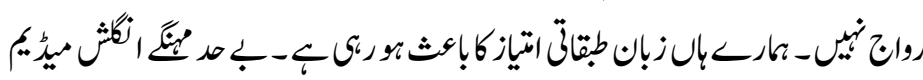

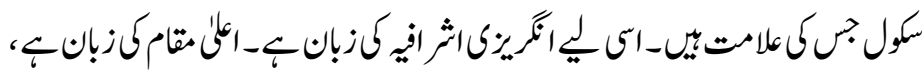

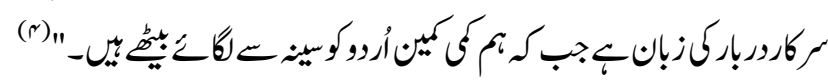

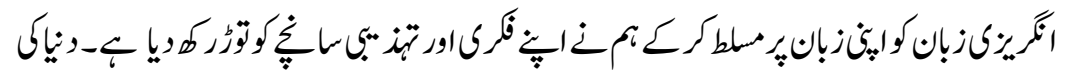

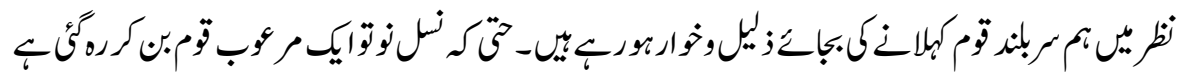

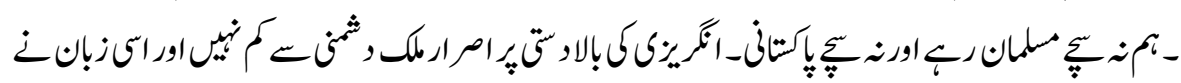

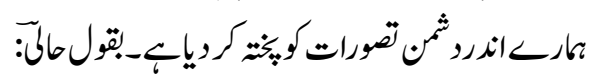

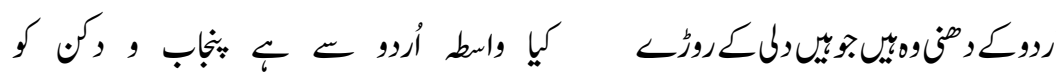

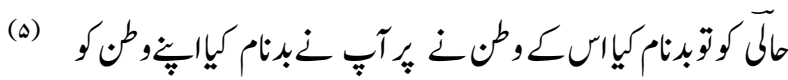

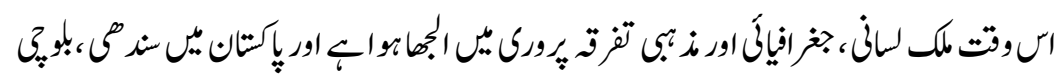

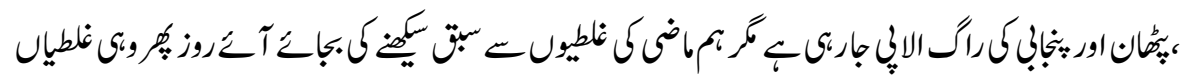

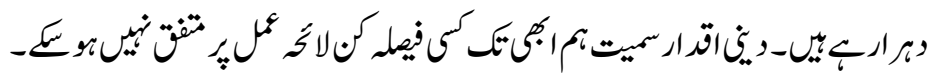

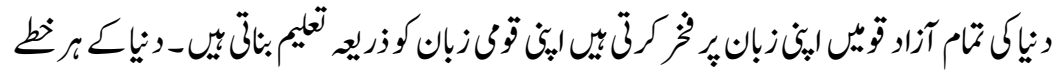

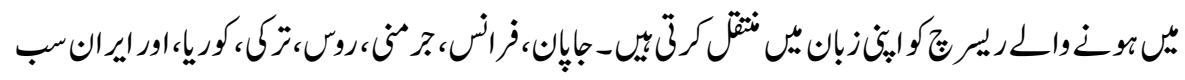

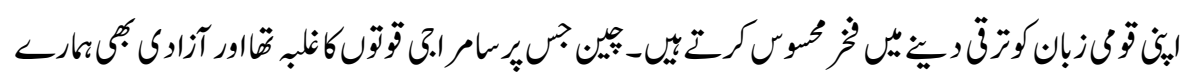

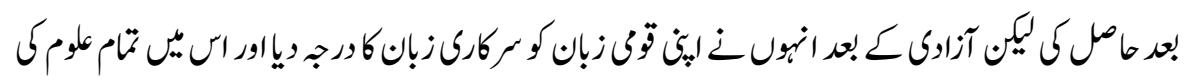




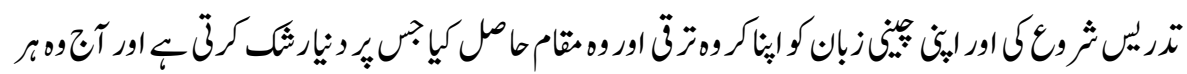

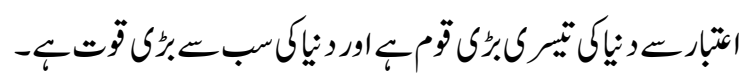

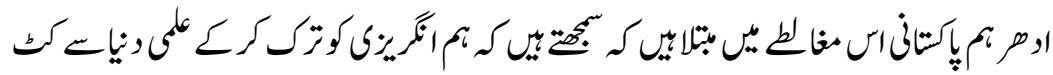

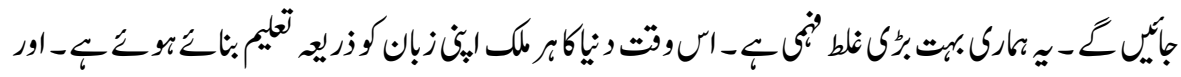

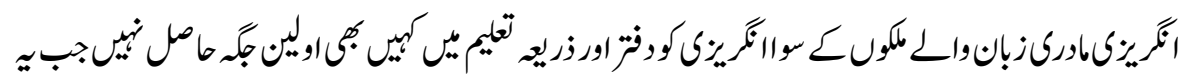

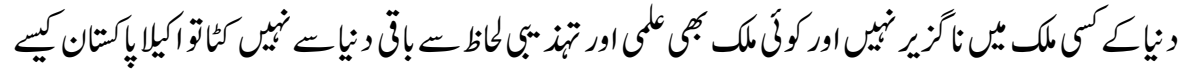

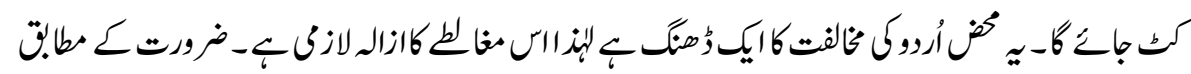

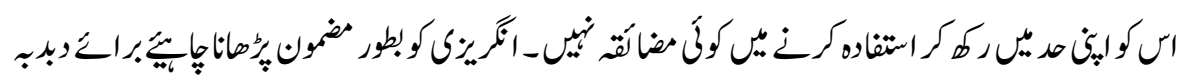

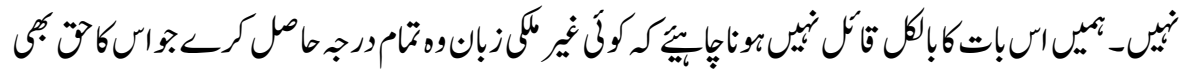

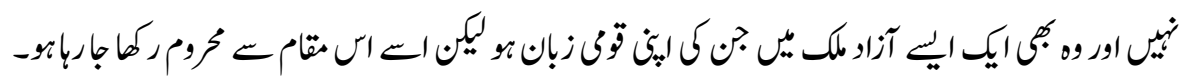

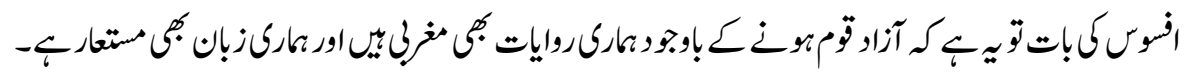

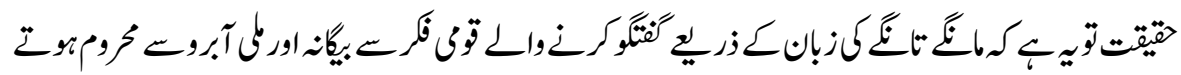

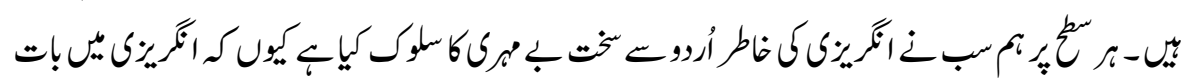

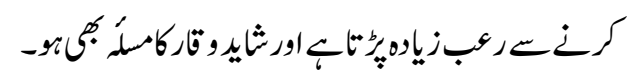

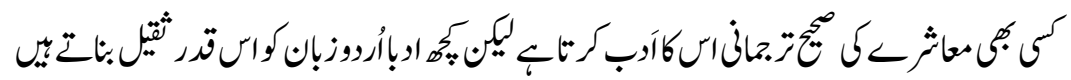

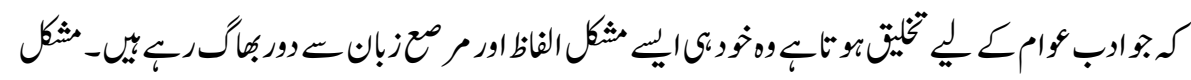

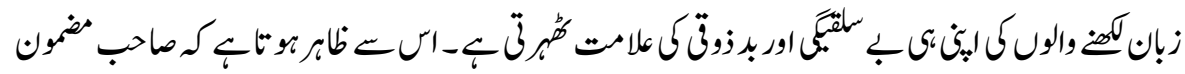

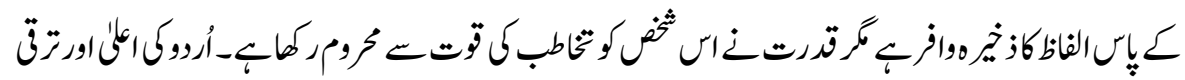

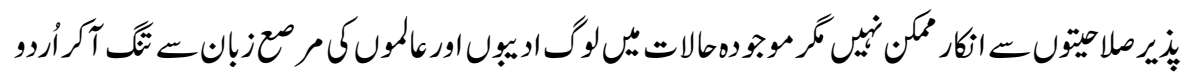

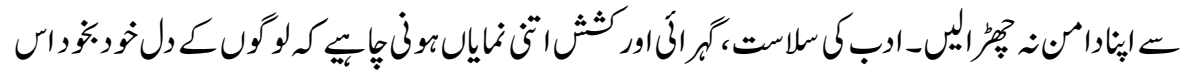

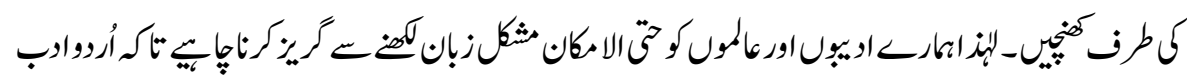

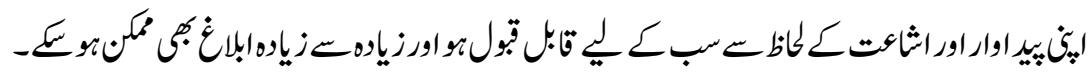




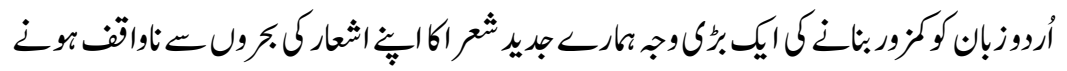

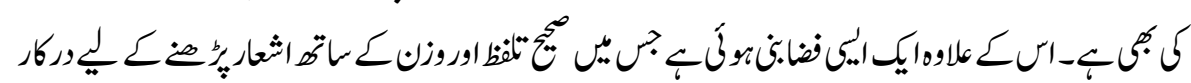

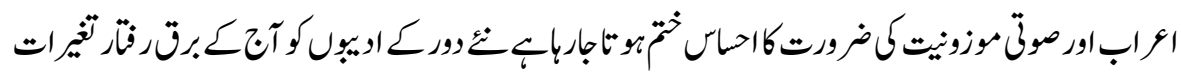

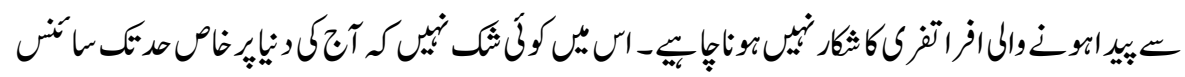

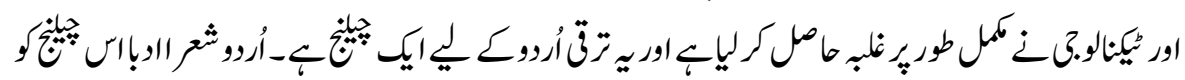

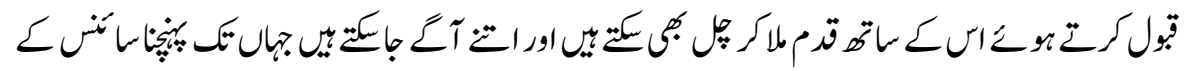

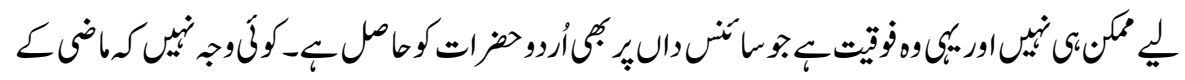

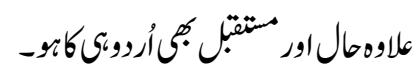

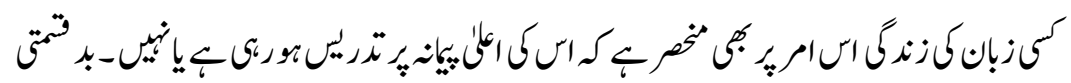

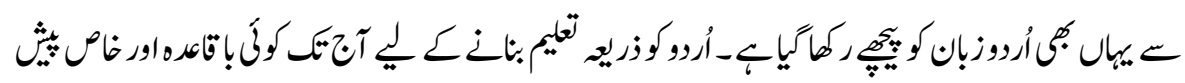

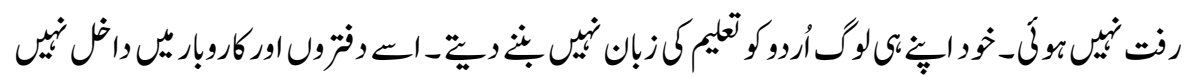

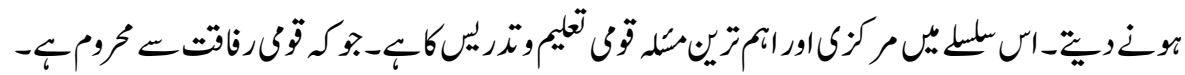

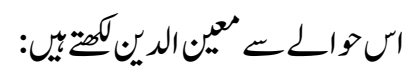

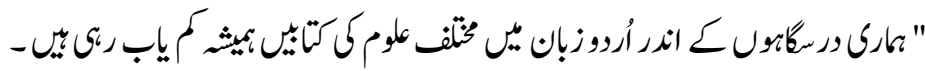

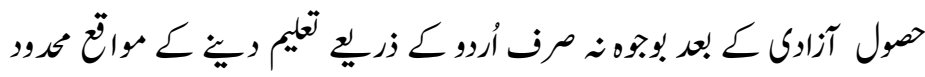

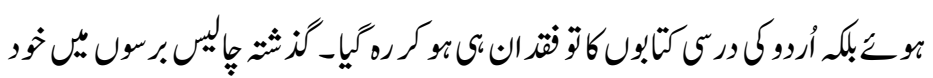

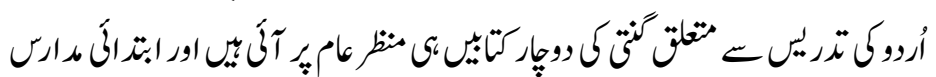

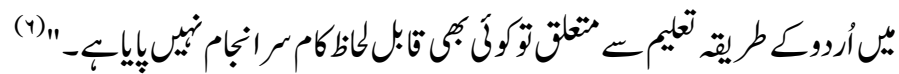

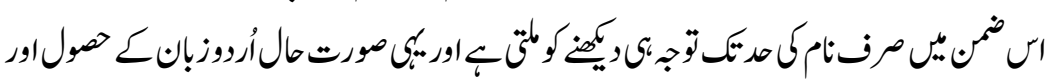

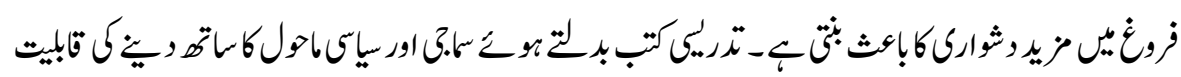

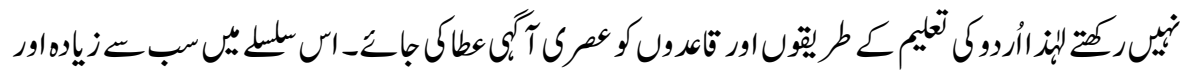

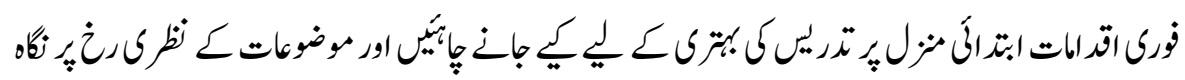




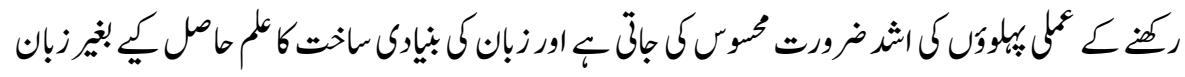

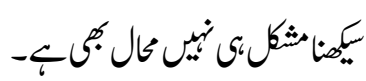

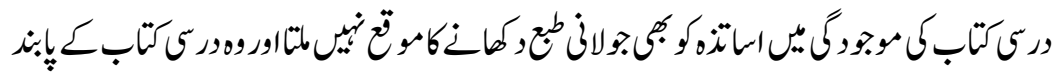

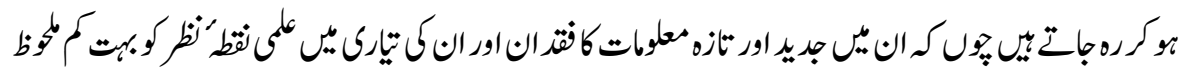

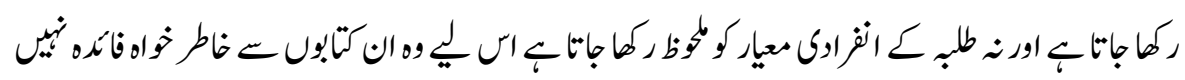

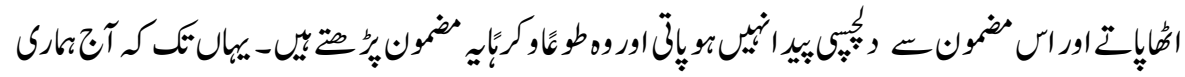

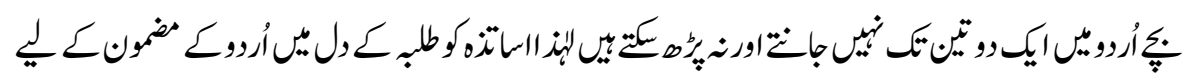

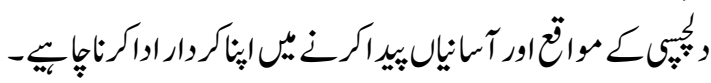

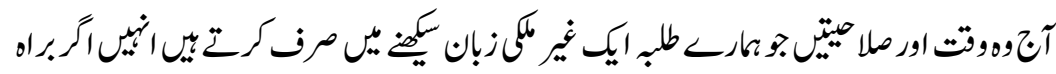

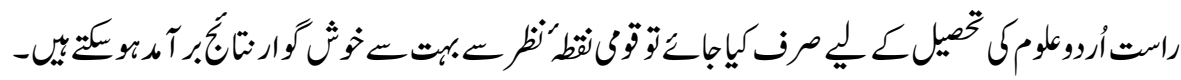

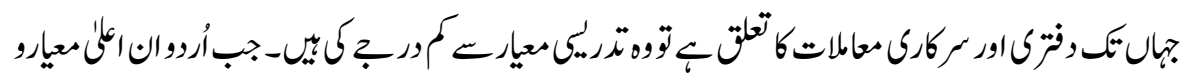

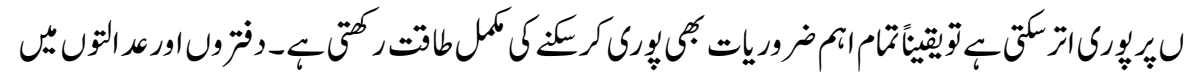

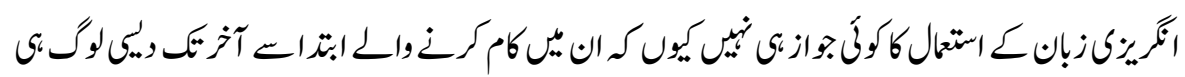

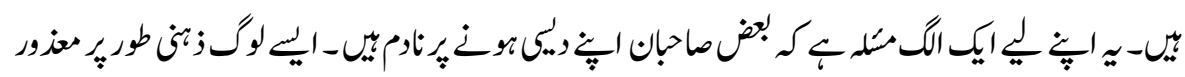

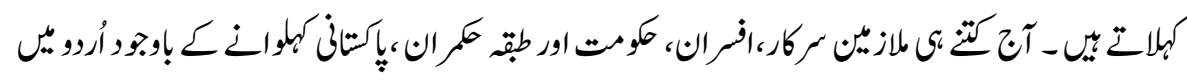

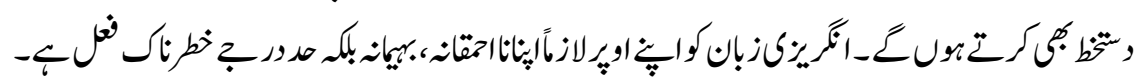

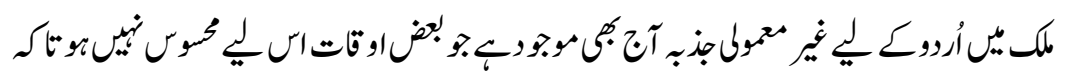

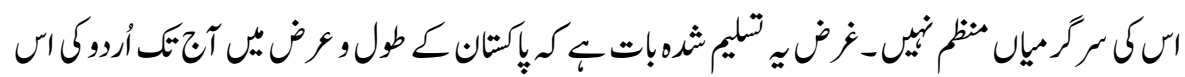

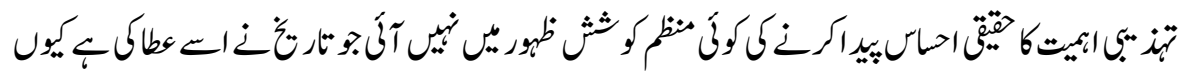

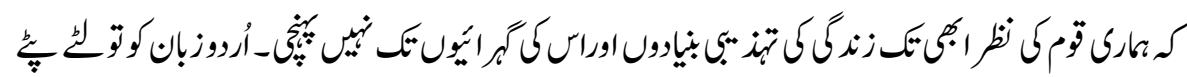

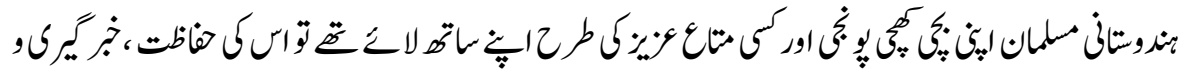

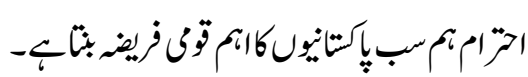




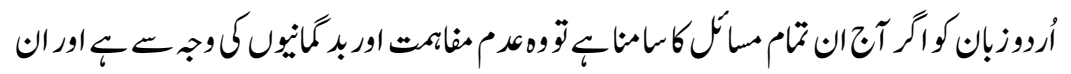

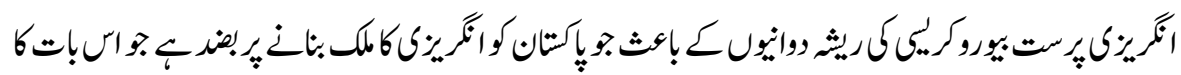

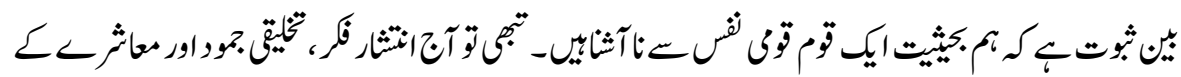

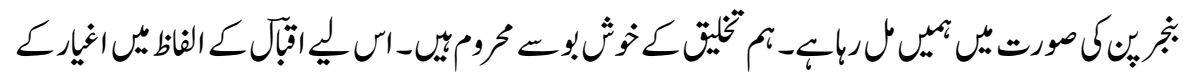

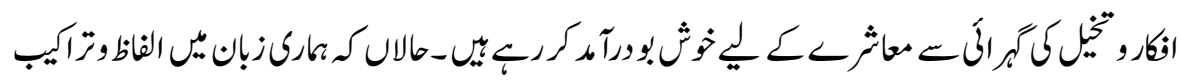

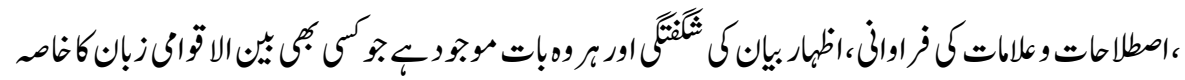

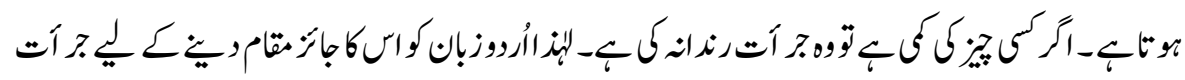

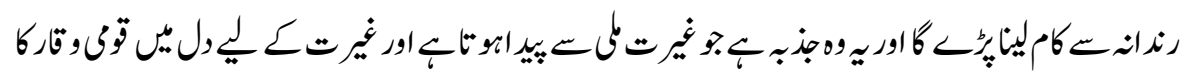

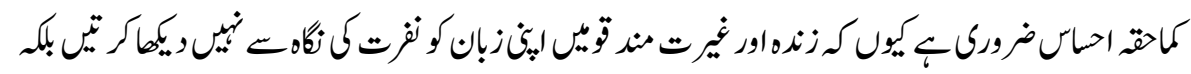

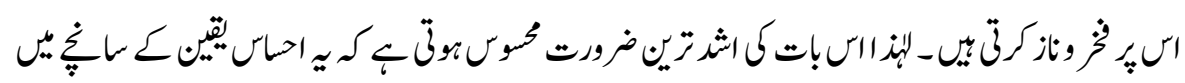

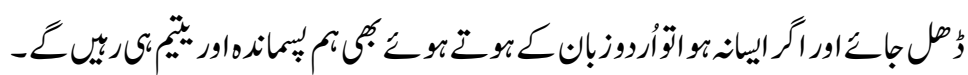

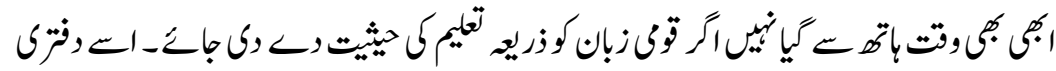

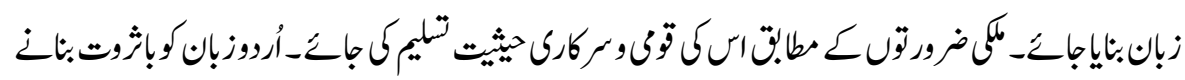

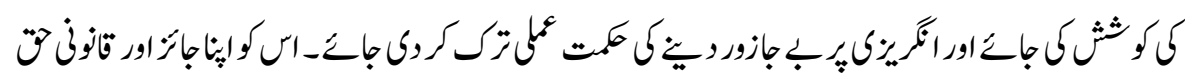

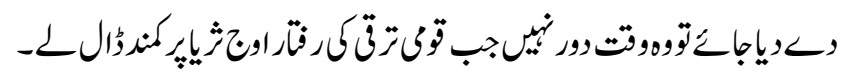

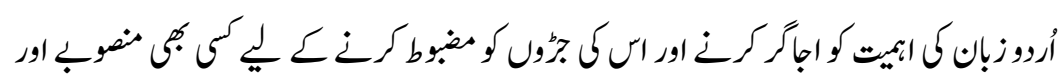

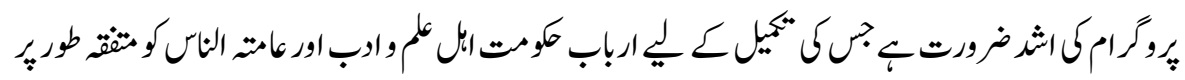

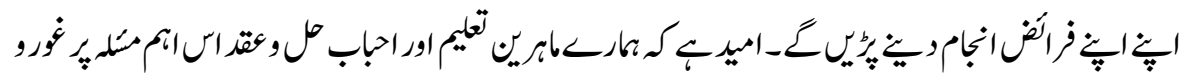

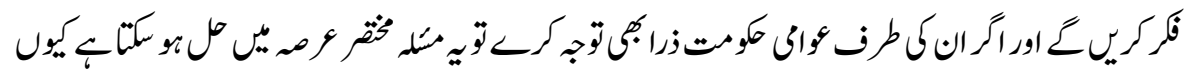

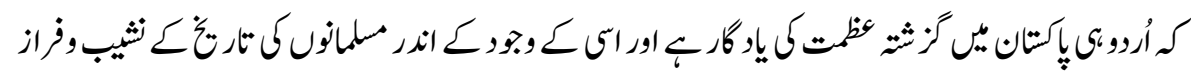




$$
\text { حوالد جات }
$$

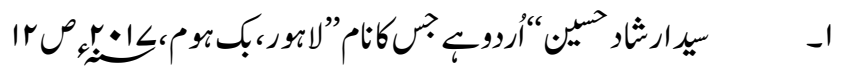

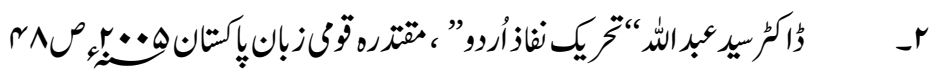

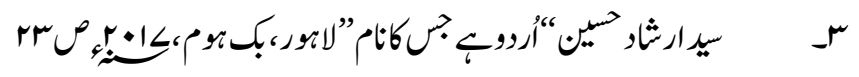

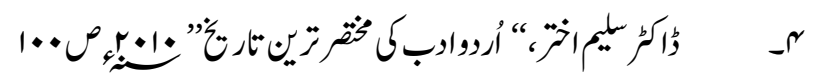

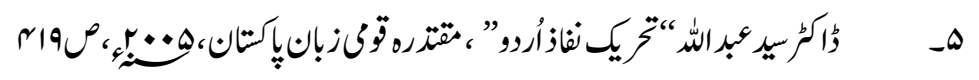

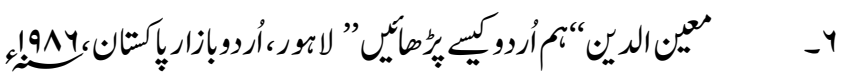

